See Article page 1965.

\section{Commentary: The uncertain fate of the pulmonary artery catheter in cardiac surgery: The difference is in the exceptions}

\author{
Brett Wakefield, MD, and Mariya Geube, MD, FASE
}

Since its introduction in the 1970s, use of the flow-directed balloon-tipped pulmonary artery catheter (PAC) has become the gold standard for guiding therapy in critically ill patients and those undergoing complex surgical procedures. These invasive catheters allow real-time measurement of cardiac output, pulmonary arterial pressure, pulmonary capillary wedge pressure, and mixed venous oxygen saturation-frequently used hemodynamic parameters to discern between different physiologic states. However, large-scale studies and meta-analyses have failed to show an outcome benefit in noncardiac critical care patients. ${ }^{1-4}$

Over the past 2 decades, PAC monitoring has become less common, although its use varies markedly among institutions and clinical settings. Of note, PAC use in cardiac surgery has not paralleled this downward trend. PACs are considered useful for guiding rational decisions concerning the administration of fluids, inotropes, and diuretics in cardiac surgery patients; however, similar to in other disciplines, this notion has been challenged multiple times over the years, with no consensus. ${ }^{5-7}$

In this issue of the Journal, Brown and colleagues ${ }^{8}$ present yet another study exploring the impact of PACs in cardiac surgery patients. Using propensity score matching, this large observational study identified 3519 pairs of patients undergoing coronary artery bypass grafting $(\mathrm{CABG})$, aortic or mitral valve surgery, or combined procedures with or without PAC placement. Surgeries included primary or reoperations, elective, or emergent cases. The authors report

\footnotetext{
From the Department of Cardiothoracic Anesthesiology, Cleveland Clinic Foundation, Cleveland, Ohio.

Disclosures: The authors reported no conflicts of interest.

The Journal policy requires editors and reviewers to disclose conflicts of interest and to decline handling or reviewing manuscripts for which they may have a conflict of interest. The editors and reviewers of this article have no conflicts of interest.

Received for publication Feb 15, 2021; revisions received Feb 15, 2021; accepted for publication Feb 17, 2021; available ahead of print Feb 22, 2021.

Address for reprints: Mariya Geube, MD, FASE, Department of Cardiothoracic Anesthesiology, Cleveland Clinic Foundation, 9500 Euclid Ave, J4-328, Cleveland, OH 44195 (E-mail: geubem@ccf.org).

J Thorac Cardiovasc Surg 2022;164:1974-5

$0022-5223 / \$ 36.00$

Copyright $(c) 2021$ by The American Association for Thoracic Surgery

https://doi.org/10.1016/j.jtcvs.2021.02.057
}

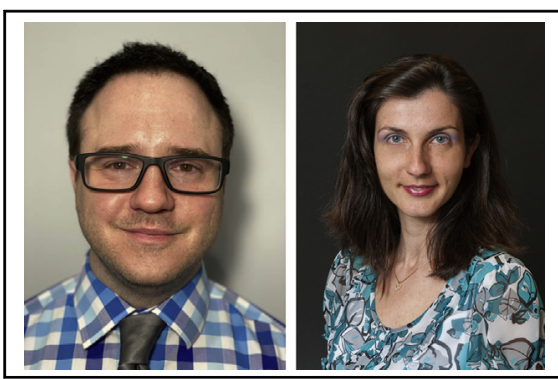

Brett Wakefield, MD, and Mariya Geube, MD, FASE

CENTRAL MESSAGE

Pulmonary artery catheters have

a limited role in low-risk cardiac

surgery, but these results should

not be extrapolated to high-

acuity complex cardiac surgery

cases.

no difference in the mortality rate between the 2 groups ( $2.4 \%$ in each group; $P=1.000$ ); however, the PAC group received more red blood cell transfusions (intraoperative, $26.3 \%$ vs $23.4 \%[P=.004]$; postoperative, $40.4 \%$ vs $35.5 \%[P<.001])$ and had a longer intensive care unit (ICU) length of stay (48 hours vs 39 hours; $P<.001$ ). Other outcomes, such as stroke, sepsis, and renal failure, were similar in the 2 groups. A subgroup analysis of PAC use in patients with recent congestive heart failure, mitral valve disease, and tricuspid valve disease also failed to show a mortality benefit.

In contrast to previously reported cardiac surgery studies, ${ }^{9-11}$ the present study includes valvular and combined procedures, in addition to coronary revascularization, in a large patient cohort.

The authors offer a thoughtful discussion of the study's limitations. In this series, patients with PACs were more likely to have a lower ejection fraction, less preoperative inotrope use, less anemia, fewer previous cardiac surgeries, and higher STS risk scores. Although propensity score matching helps address this concern, it does not eliminate selection bias. An additional limitation is the lack of homogeneity among management decisions based on PAC data. The authors provide insight into the finding of increased blood transfusion and ICU length of stay. Administering a unit of blood to increase the mixed venous saturation and delaying transfer to the floor until the numbers "normalize" is common practice. The authors note that sometimes the PAC data lead to overtreatment, which may be harmful, 
while admitting that there is no specific protocol for hemodynamic management based on the PAC measurements at their institution. In our opinion, this is not a problem of the monitoring device, but a problem of the clinical providers interpreting the data. Without a protocolized management strategy, it is challenging to assess the efficacy of decisions or interventions based on clinical outcomes.

The explanation for the lack of benefit of PACs in cardiac surgery patients remains speculative. It could be that patients at low surgical risk do well with or without extensive hemodynamic monitoring. Perhaps PACs are most useful in complex, high-risk patients. We believe that patient selection is of paramount importance; in our opinion, the difference is in the exceptions. The present study did not include any patients who underwent ventricular assist device implantation, pulmonary endarterectomy, thoracoabdominal aneurysm repair, heart and lung transplantation, endocarditis surgery, pericardiectomy, and rheumatic heart disease, to mention a few. Furthermore, the average ejection fraction of the cohort was $55 \%$, and such variables as pulmonary hypertension, right ventricular dysfunction, and diastolic dysfunction, which are major indications for PAC insertion, were not included in the matching process. Similarly, propensity score matching grouped mitral valve patients together, ignoring the comparatively more complex physiology of mitral stenosis compared with regurgitation.

Now, should we abandon the use of PACs in cardiac surgery? Assessment of PAC effectiveness is not straightforward, given use/nonuse biases and considerable differences in the interpretation of PAC measurements among practitioners. Based on available data, PACs do not add benefit for "routine" or low-risk cardiac surgery. Nonetheless, PACs will not be leaving the cardiac operating room. Considering that these studies exclude the patient populations potentially most benefited by PACs, physicians will continue to rely on the data derived from these catheters in high-acuity patients presenting for complex cardiac surgery. Thus, the future research question to answer is not "yes or no" to PACs, but rather "when and in whom"because the difference is in the exceptions.

\section{References}

1. Binanay C, Califf RM, Hasselblad V, O’Connor CM, Shah MR, Sopko G, et al Evaluation study of congestive heart failure and pulmonary artery catheterization effectiveness: the ESCAPE trial. JAMA. 2005;294:1625-33.

2. Sandham JD, Hull RD, Brant RF, Knox L, Pineo GF, Doig CJ, et al. A randomized, controlled trial of the use of pulmonary-artery catheters in high-risk surgical patients. N Engl J Med. 2003;348:5-14.

3. Rajaram SS, Desai NK, Kalra A, Gajera M, Cavanaugh SK, Brampton W, et al. Pulmonary artery catheters for adult patients in intensive care. Cochrane Database Syst Rev. 2013;CD003408.

4. Shah MR, Hasselblad V, Stevenson LW, Binanay C, O'Connor CM, Sopko G, et al. Impact of the pulmonary artery catheter in critically ill patients: metaanalysis of randomized clinical trials. JAMA. 2005;294:1664-70.

5. Schwann NM, Hillel Z, Hoeft A, Barash P, Möhnle P, Miao Y, et al. Lack of effectiveness of the pulmonary artery catheter in cardiac surgery. Anesth Analg. 2011; 113:994-1002.

6. Shaw AD, Mythen MG, Shook D, Hayashida DK, Zhang X, Skaar JR, et al. Pulmonary artery catheter use in adult patients undergoing cardiac surgery: a retrospective, cohort study. Perioper Med (Lond). 2018;7:24

7. Brovman EY, Gabriel RA, Dutton RP, Urman RD. Pulmonary artery catheter use during cardiac surgery in the United States, 2010 to 2014. J Cardiothorac Vasc Anesth. 2016;30:579-84.

8. Brown JA, Aranda-Michel E, Kilic A, Serna-Gallegos D, Bianco V, Thoma FW, et al. The impact of pulmonary artery catheter use in cardiac surgery. $J$ Thorac Cardiovasc Surg. 2022;164:1965-73.e6.

9. Xu F, Wang Q, Zhang H, Chen S, Ao H. Use of pulmonary artery catheter in coronary artery bypass graft. Costs and long-term outcomes. PLoS One. 2015;10: e0117610.

10. Tuman KJ, McCarthy RJ, Spiess BD, DaValle M, Hompland SJ, Dabir R, et al Effect of pulmonary artery catheterization on outcome in patients undergoing coronary artery surgery. Anesthesiology. 1989;70:199-206.

11. Ramsey SD, Saint S, Sullivan SD, Dey L, Kelley K, Bowdle A. Clinical and economic effects of pulmonary artery catheterization in nonemergent coronary artery bypass graft surgery. J Cardiothorac Vasc Anesth. 2000;14:113-8. 